\title{
MONTAJE PARA UNA EXPOSICION DE PINTURA EN EL PALACIO DE VILLAHERMOSA. REMODELADO - MADRID
}

\author{
(SETTING UP OF A PAINTINGS EXPOSITION IN THE REMODELLED VILLAHERMOSA. \\ PALACE - MADRID)
}

Francisco Rodriguez de Partearroyo, Arquitecto

\section{RESUMEN}

Se describen en este artículo los trabajos de remodelación del palacio de Villahermosa, con vistas a su integración como parte del complejo del Museo del Prado. El edificio había sido anteriormente acondicionado como sede de una entidad bancaria.

La remodelación ha consistido fundamentalmente en adecuar el interior del edificio para conseguir un ambiente análogo al de las salas del Museo mediante la disposición de muros, revestimientos, etc., capaces de crear dicho ambiente.

\section{SUMMARY}

The works for the remodelling of the Villahermosa Palace in order to integrate it as a part of the complex of the Prado Museum are reported. This building was before adapted for a bank head office.

The remodelling was carried out specially on the building indoors to obtain the same ambient that this of the Museum House by means of the arrangement of the walls, of the linings, etc.

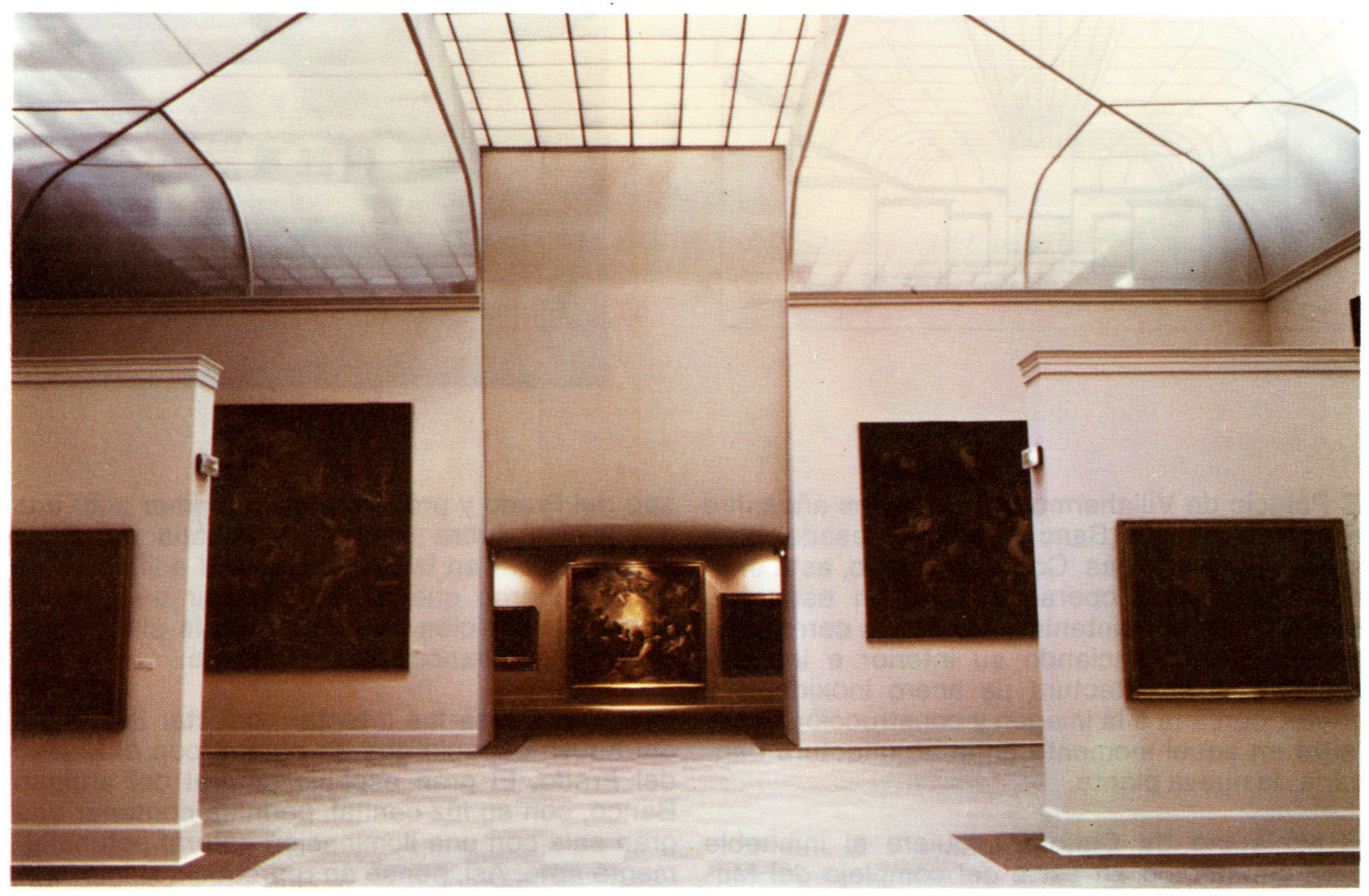




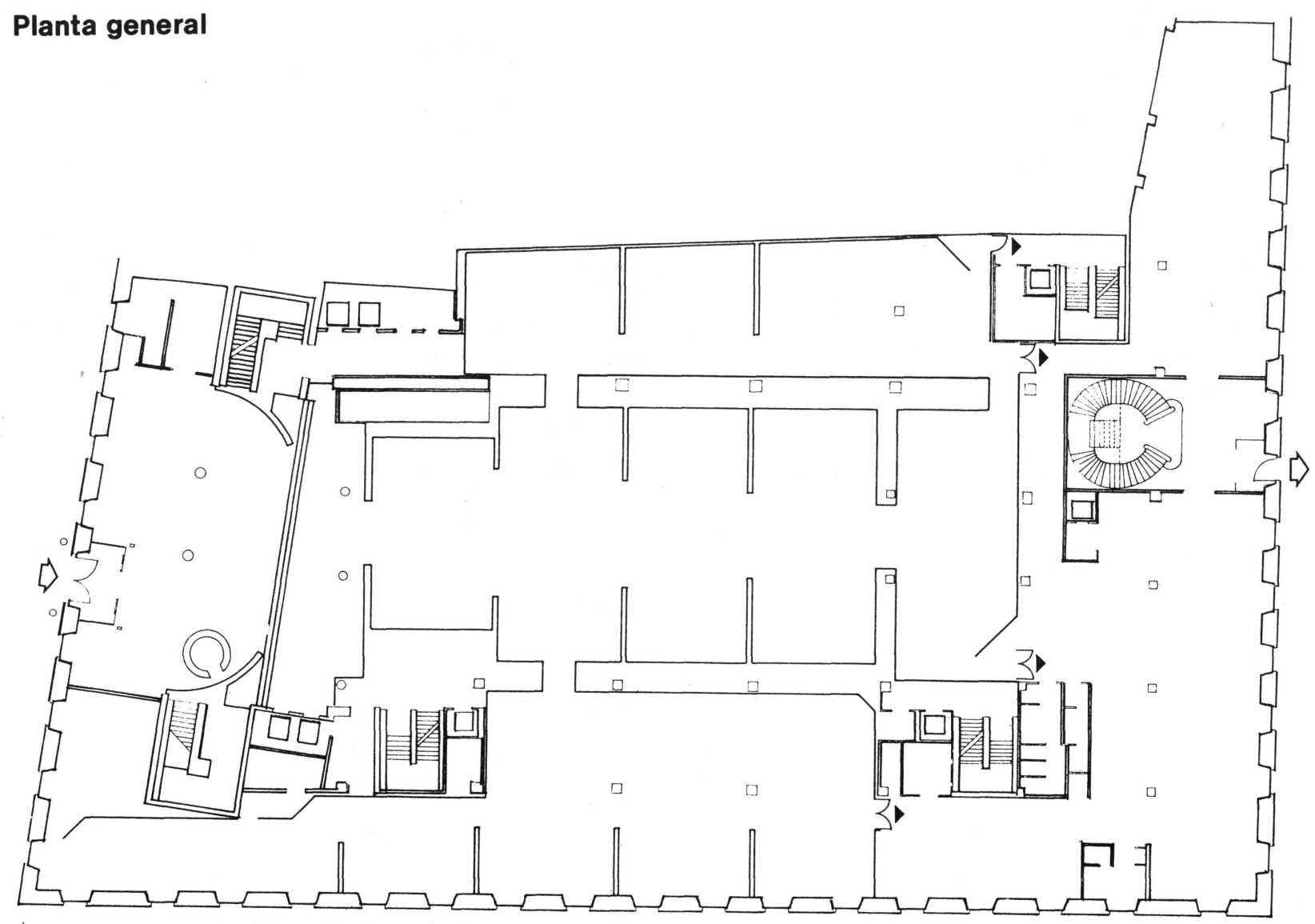

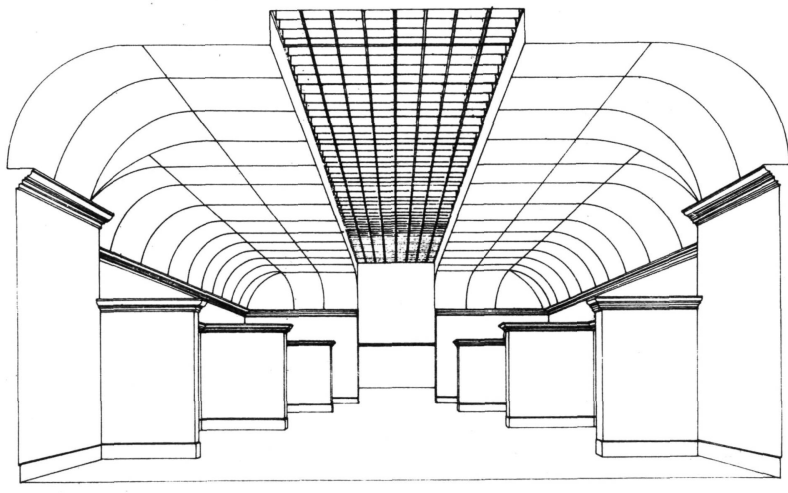

Diseño.

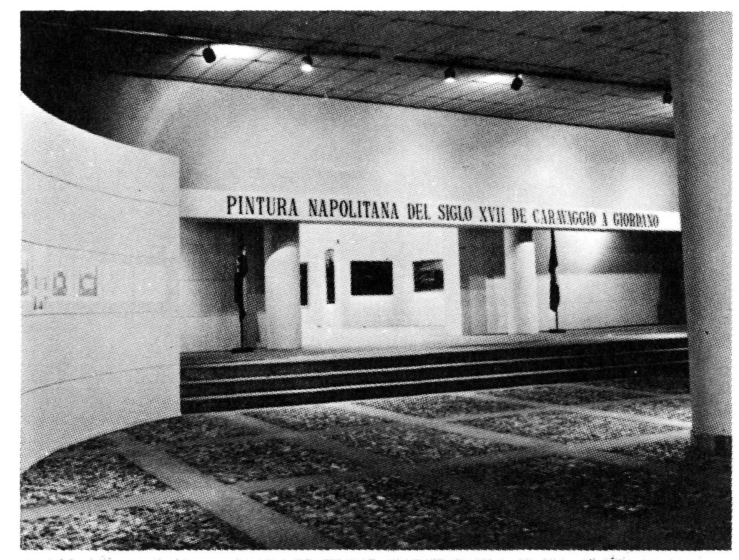

El Palacio de Villahermosa, hace unos años, fue adquirido por la Banca López-Quesada para sede de sus oficinas. Con este motivo, esta entidad realizó una operación que, en esquema, consistió en el mantenimiento de los cerramientos exteriores, vaciando su interior e introduciendo una arquitectura de acero inoxidable y cristal, cercana a la imagen y construcción imperante en aquel momento en la arquitectura bancaria de nueva planta.

El Ministerio de Cultura adquiere el inmueble para constituirlo en parte del complejo del Mu- seo del Prado y programa como primer acto una exposición sobre Pintura Napolitana del Siglo XVII, a ubicar en la planta baja del edificio. Este es el encargo que recibo: diseñar un montaje para la exposición de pintura, en la planta baja de la antigua banca López-Quesada.

La primera idea fue intentar conectar la imagen del nuevo espacio que se creaba con el Museo del Prado. El gran espacio central del antiguo Banco, con su luz cenital, permitia contener una gran sala con una iluminación natural potencialmente apta. Así, pensé en reproducir, reinterpre- 


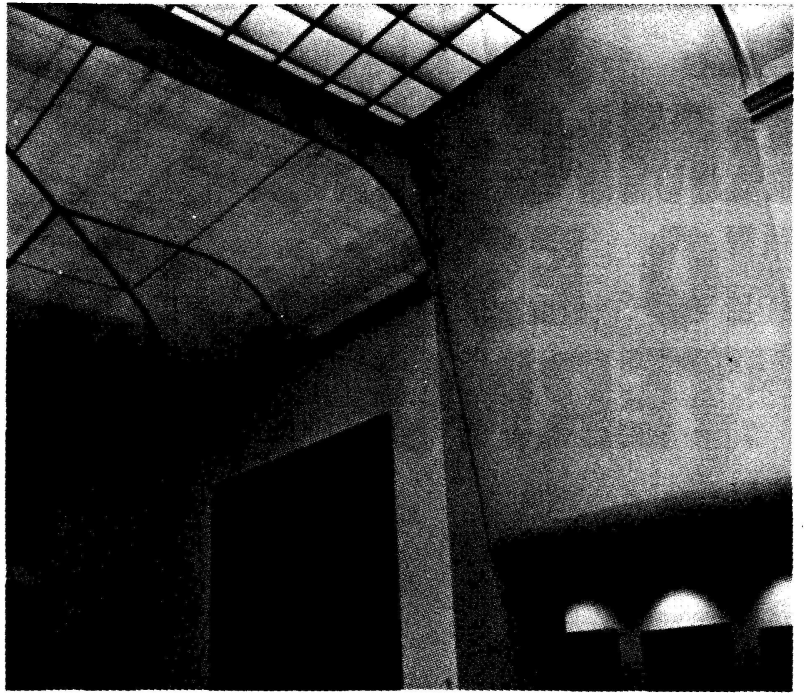

tando sus elementos, una sala del Museo del Prado seccionada. Guardaria sus proporciones, manipularia evidentemente su construcción y materiales, su lenguaje decorativo y la textura de sus paredes.

Asi, la bóveda se convierte en un techo de tela que opera como gran difusor que consigue una iluminación no superior a 150 lux sin crear sombras y revela su condición de provisionalidad.
El eje de la sala central se convierte en una hendidura que permite conocer la actuación anterior, significándose los planos de la «sección» con un color gris que se diferencia del color arena de los paramentos verticales. En este eje central $-y$ en el punto de acceso a la sala, que es el de "sorpresa"-se provoca un "trompe l'oeil» con la disposición de los muretes transversales, que refuerzan el sentido longitudinal de las salas del Museo del Prado. Aun en las puertas de acceso a las salas adyacentes se vislumbra la intersección del volumen anterior de la sala con la intersección que se realiza.

En el resto de las salas la actuación se limita a envolver el espacio, tanto los paramentos verticales como el techo, en el que se utiliza la misma tela de la sala central. Con la moqueta en baldosas ignifugas y mediante un fajeado perimetral más oscuro, se crea una barrera sicológica de protección a los cuadros.

La actuación en el vestíbulo se limita a la corrección de los ejes de entrada por medio de dos falsos muros curvos que remiten al eje de la sala central y permite la colocación del puesto de control. Así, la intervención es progresiva, dejando constancia de lo efímero de la actuación, pudiendo en cualquier momento devolver al edificio su anterior configuración.

\section{NOTA IMPORTANTE:}

Ante la experiencia adquirida en los últimos años, y con la incorporación de nuevos miembros al Comité de Redacción, se pretende, desde el primer número de 1987, concentrar mayor y mejor información en menos fascículos. Concretamente se publicarán seis números al año, en los cuales se intentará superar el contexto de la revista -según proceda- asi como incrementar mayor número de ilustraciones a color (dentro de las limitaciones presupuestarias) que redundará notablemente en la presentación gráfica.

No se alterará el precio de la suscripción (permanece inamovible desde hace años). Aunque se entreguen 6 números al año, en lugar de 10, los aumentos acumulados de los costos, el mayor número de páginas, mejor contenido y superior calidad compensarán la diferencia en fascículos. 